\title{
Lessons for the clinical nephrologist: recurrent pregnancy-associated thrombotic microangiopathy (TMA) with a known complement mutation and features of preeclampsia; a diagnostic and therapeutic dilemma
}

\author{
Priscilla Smith $^{1}$ - Alyaa Abdelmaguid ${ }^{1,2} \cdot$ Katherine Clark $^{1,3} \cdot$ Kate Bramham $^{1,3}$
}

Received: 6 November 2020 / Accepted: 21 March 2021 / Published online: 7 June 2021

(c) Crown 2021

Keywords Pregnancy $\cdot$ Thrombotic microangiopathy $\cdot$ TMA $\cdot$ aHUS $\cdot$ Preeclampsia

\section{The case}

We report a case of recurrent thrombotic microangiopathy (TMA) in pregnancy in a 22-year-old with previous liver transplantation for congenital hepatic fibrosis. She was taking insulin and labetalol for chronic hypertension and gestational diabetes, and tacrolimus. She presented at 18-weeks' gestation with generalized swelling, breathlessness, $30 \mathrm{~kg}$ weight gain, hypertension $(150 / 100 \mathrm{mmHg})$, proteinuria (urinary protein: creatinine ratio (uPCR) $201.3 \mathrm{mg} / \mathrm{mmol}$ ) with acute kidney injury, deranged liver function tests, thrombocytopenia and biochemical and haematological features of TMA (Table 1). Chest X-ray showed left pleural effusion, but renal ultrasound, lower limb Dopplers and echocardiogram were normal. Differential diagnoses for pregnancy-associated TMA were considered (Fig. 1).

Thrombotic Thrombocytopenic Purpura was excluded (ADAMTS-13 activity 22\%), connective tissue, autoimmune and thrombophilia investigations were negative (Antiphospholipid-antibodies, ANA, Anti-dsDNA, anti-Scl-70, AntiGBM $(<0.8 \mathrm{U} / \mathrm{ml}), \mathrm{C} 3$-nephritic factor, prothrombin gene and factor-V Leiden gene). Tacrolimus concentration was within the therapeutic target range $(8.8 \mu \mathrm{g} / \mathrm{l})$. Renal biopsy

Kate Bramham

kate.bramham@kcl.ac.uk

1 King's Kidney Care, King's College Hospital and King's College London, NHS Foundation Trust, Denmark Hill, London SE5 9RS, UK

2 Medical Research Institute, Alexandria University, Alexandria, Egypt

3 Department of Women and Children's Health, King's College London, London, UK was not feasible due to clinical status and low platelet count. Intrauterine death occurred at 22-weeks' gestation. Subsequent genetic testing confirmed complement mutation (heterozygous c. $1855 \mathrm{G}>\mathrm{A}$ (p.Val619Met) variant in exon 15; C3 gene), which was not present in stored liver donor DNA.

Pre-pregnancy counselling was provided by a specialist nephrologist and obstetrician about future pregnancy risk. Approval for eculizumab use in future pregnancies if TMA reoccurred was obtained in view of the complement mutation and potential risk of recurrent disease [1] but prophylaxis was not advised. She was vaccinated against pneumococcal and meningococcal infections.

In her next pregnancy (18 months later), she developed recurrent TMA at 22 weeks' gestation [serum creatinine $199 \mu \mathrm{mol} / \mathrm{l}$ (baseline $60 \mu \mathrm{mol} / \mathrm{l}$ ), platelets $50 \times 10^{9} / 1$ and anaemia (Hb $107 \mathrm{~g} / \mathrm{l})]$. Blood pressure was 160/100 mmHg, and she had substantial peripheral oedema. Other investigations were unremarkable and fetal scans were reassuring. Placental Growth Factor concentration (PLGF) was low $<12 \mathrm{pg} / \mathrm{ml}$.

Eculizumab (900 mg) was commenced. However, renal function continued to deteriorate, so a second dose $(1200 \mathrm{mg})$ was given on day 5 which led to stabilization and improvement in all markers (Fig. 2). Transient creatinine rise following dose was attributed to concurrent infection. Fetal demise occurred on day 8 of treatment. Placental histology showed "features of hypoperfusion including intervillous fibrin deposition, fibrin thrombi and foci of ischaemic type necrosis. Calcification and syncytial knots noted, which is suggestive of pre-eclampsia".

Uncertainty surrounding the diagnosis of preeclampsia or aHUS was communicated and counselling regarding potential risks and benefits of prophylactic eculizumab in 
Table 1 Results (pregnancy bloods are the most extreme results recorded)

\begin{tabular}{|c|c|c|c|c|}
\hline & $\begin{array}{l}2015 \\
\text { Non-pregnant }\end{array}$ & $\begin{array}{l}2016 \\
\text { Pregnancy }\end{array}$ & $\begin{array}{l}2018 \\
\text { Pregnancy }\end{array}$ & $\begin{array}{l}2019 \\
\text { Non-Pregnant }\end{array}$ \\
\hline Serum creatinine $(\mu \mathrm{mol} / \mathrm{l})$ & 52 & $126 \uparrow$ & $199 \uparrow$ & 69 \\
\hline Haemoglobin (g/dl) & 126 & $94 \downarrow$ & $87 \downarrow$ & 138 \\
\hline Platelets (cells $\left./ 10^{9} \mu \mathrm{l}\right)$ & 72 & $13 \downarrow$ & $43 \downarrow$ & 89 \\
\hline Haptoglobin (mg/dl) & - & $<0.1 \downarrow$ & $<0.1 \downarrow$ & - \\
\hline Blood film & - & Occasional fragments & $\begin{array}{l}\text { No significant frag- } \\
\text { ments }\end{array}$ & - \\
\hline Absolute reticulocyte count $\left(10^{9} / 1\right)$ & - & $311.5 \uparrow$ & $482.6 \uparrow$ & - \\
\hline Lactate dehydrogenase (U/l) & - & $557 \uparrow$ & $559 \uparrow$ & - \\
\hline Direct antiglobulin test & - & Negative & Negative & - \\
\hline Total bilirubin $(\mu \mathrm{mol} / \mathrm{l})$ & 27 & $65 \uparrow$ & $57 \uparrow$ & 37 \\
\hline Aspartate transaminase (U/l) & 51 & $79 \uparrow$ & $101 \uparrow$ & 38 \\
\hline Activated partial thromboplastin time ratio & 1.11 & $1.2 \uparrow$ & $1.18 \uparrow$ & 1.07 \\
\hline Tacrolimus level $(\mu \mathrm{g} / \mathrm{l})$ & 5 & $12.6 \uparrow$ & $10.9 \uparrow$ & 8.0 \\
\hline $\mathrm{C} 3(\mathrm{~g} / \mathrm{l})$ & 0.58 & $0.61 \downarrow$ & $0.61 \downarrow$ & 0.66 \\
\hline $\mathrm{C} 4(\mathrm{~g} / \mathrm{l})$ & 0.14 & $0.10 \downarrow$ & $0.07 \downarrow$ & - \\
\hline Anti-dsDNA IU/ml & - & 1 & $<1$ & - \\
\hline
\end{tabular}

Rise in creatinine occurred prior to tacrolimus level increase

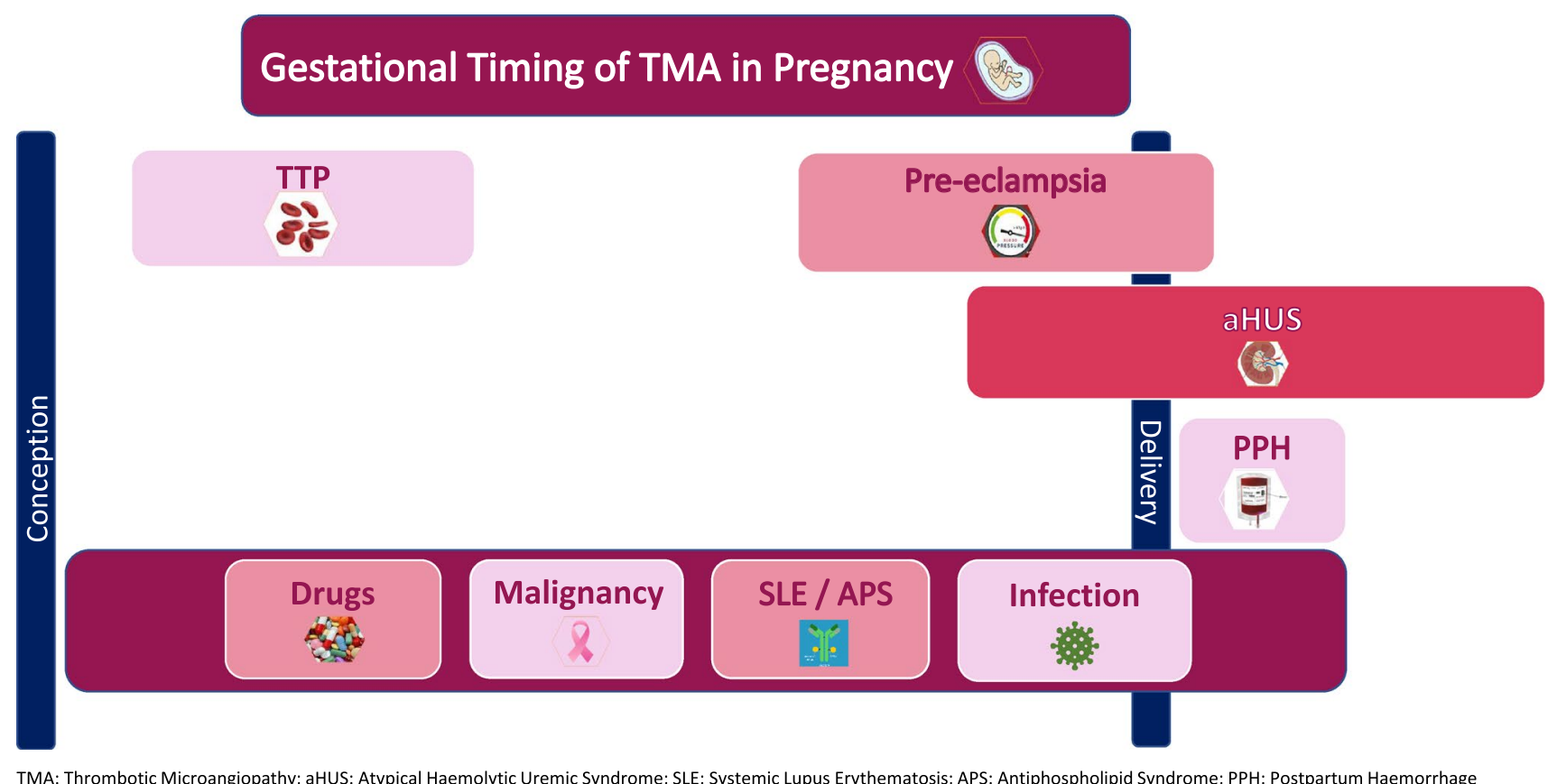

Fig. 1 Gestational timing of thrombotic microangiopathy in pregnancy. TMA thrombotic microangiopathy, aHUS atypical haemolytic uremic syndrome, SLE systemic lupus erythematosus, APS antiphospholipid syndrome, $P P H$ postpartum haemorrhage

a future pregnancy was provided. She was advised to use effective contraception and is considering surrogacy for future pregnancies.

\section{Discussion}

What is the association between pregnancy and aHUS? 


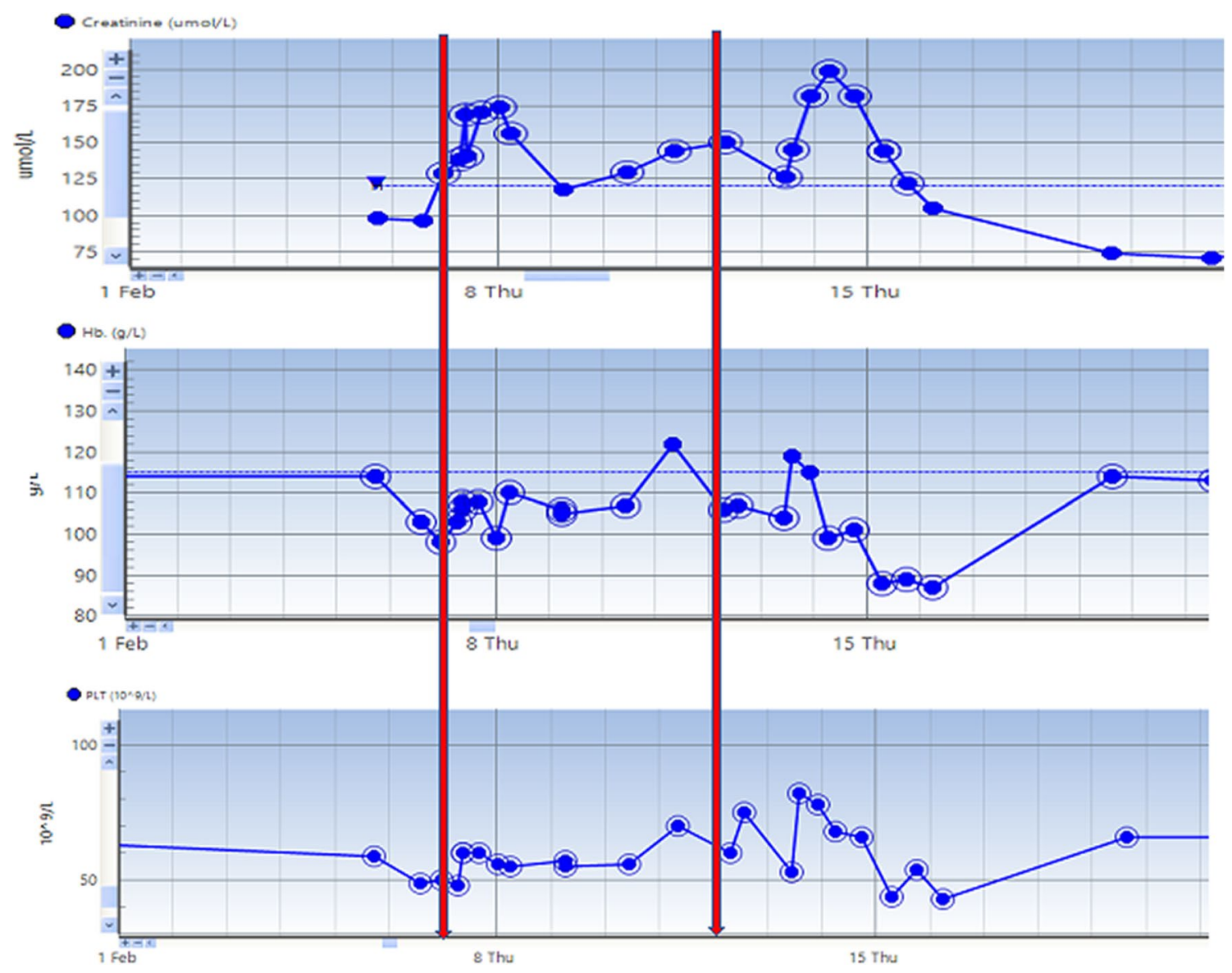

Fig. 2 Serum creatinine, haemoglobin and platelet changes in second pregnancy

Atypical Haemolytic Uraemic Syndrome (aHUS) is rare and estimated to affect 1 in 25,000 pregnancies, typically presenting with acute kidney injury (AKI), microangiopathic haemolytic anaemia and thrombocytopenia [1], and is associated with substantial morbidity and mortality [2]. Primary aHUS is associated with complement gene mutations [3], and $21 \%$ of cases in women of childbearing age are associated with pregnancy [4]. Diagnosis is challenging due to common features with pre-eclampsia, connective tissue disorders and thrombotic thrombocytopenic purpura. Early confirmation of TMA aetiology is critical to facilitate appropriate management.

\section{Could this be a drug-induced TMA?}

Tacrolimus may cause TMA, but reported cases are few and pathophysiology remains uncertain. Idiosyncratic immune reactions and dose-related phenomena are reported even with therapeutic concentrations [S1]. Endothelial activation and platelet aggregation associated with tacrolimus may lead to TMA, which usually resolve with withdrawal; however,
TMA may be refractory to withdrawal associated with complement activation. In this case, the tacrolimus dose was stable and trough levels were therapeutic $(8.8 \mu \mathrm{g} / \mathrm{l})$, which does not preclude a drug effect, but TMA resolution postpartum despite continuing tacrolimus makes this trigger less likely.

\section{How do liver transplantation and pregnancy affect complement production?}

In silico analysis of the reported complement mutation suggested the variant may be a rare benign polymorphism [5], but deleterious effects were not excluded. The liver produces $>90 \%$ of circulating C3 [6], but transplant recipients with discordant $\mathrm{C} 3$-allotypes have extrahepatic $\mathrm{C} 3$ upregulation for up to a year post-transplant [7]. Liver transplantation occurred 4-years prior, but pregnancy-associated upregulation of extrahepatic complement may increase the impact of the recipient $\mathrm{C} 3$ mutation. 


\section{Can you use Eculizumab in pregnancy?}

Eculizumab is not licensed for use in pregnancy, but several cases have now been reported with successful renal outcomes [8]. However, fetal and neonatal mortality associated with pregnancy-associated TMA is high and we propose that disease processes rather than eculizumab therapy led to fetal demise. In view of assumed pregnancy-associated plasma volume expansion, a higher 2nd induction dose (1200 mg) was used, with haematological and biochemical response. In keeping with our case, others with pregnancy-associated TMA have successfully stopped treatment without recurrence [9], but optimal timing and risk of relapse remains unknown.

Eculizumab has been detected in umbilical cord blood [S2], no adverse short-term effects have been reported but long-term outcomes are undetermined [S3].

\section{Is this all just preeclampsia?}

Diagnostic uncertainty of pregnancy-associated TMA is highlighted. Low PIGF and placental histology were suggestive of placental insufficiency; however, placental impact of the complement mutation is unclear. Prolongation of pregnancy with renal recovery in severe early preeclampsia has been reported in postpartum TMA with eculizumab treatment [S4-6]. A phase-1 trial of eculizumab in HaemolysisElevated-Liver-enzymes-Low-Platelet Syndrome may provide further insight [S7]. Better data describing temporal changes in TMA parameters in pregnancy are likely to facilitate earlier diagnosis and improve maternal and neonatal outcomes.

Funding No funding or financial support was received for the production of this manuscript.

\section{Declarations}

Conflict of interest The authors have no conflict of interests to declare.

Ethical standards This study was approved by the local Ethics Committee and was performed according to the Declaration of Helsinki. This article does not contain any studies with human participants or animals performed by any of the authors.
Informed consent The patient presented in this report has prospectively given written consent for this report to be published.

Open Access This article is licensed under a Creative Commons Attribution 4.0 International License, which permits use, sharing, adaptation, distribution and reproduction in any medium or format, as long as you give appropriate credit to the original author(s) and the source, provide a link to the Creative Commons licence, and indicate if changes were made. The images or other third party material in this article are included in the article's Creative Commons licence, unless indicated otherwise in a credit line to the material. If material is not included in the article's Creative Commons licence and your intended use is not permitted by statutory regulation or exceeds the permitted use, you will need to obtain permission directly from the copyright holder. To view a copy of this licence, visit http://creativecommons.org/licenses/by/4.0/.

\section{References}

1. Gupta M, Feinberg BB, Burwick RM (2018) Thrombotic microangiopathies of pregnancy: differential diagnosis. Pregnancy Hypertens 12:29-34. https://doi.org/10.1016/j.preghy.2018.02.007

2. Noris M, Remuzzi G (2009) Atypical hemolytic-uremic syndrome. N Engl J Med 361(17):1676-1687. https://doi.org/10. 1056/NEJMra0902814

3. Noris $\mathrm{M}$ et al (2010) Relative role of genetic complement abnormalities in sporadic and familial aHUS and their impact on clinical phenotype. Clin J Am SocNephrol 5(10):1844-1859. https:// doi.org/10.2215/CJN.02210310

4. Fakhouri F et al (2010) Pregnancy-associated hemolytic uremic syndrome revisited in the era of complement gene mutations. J Am SocNephrol 21(5):859-867. https://doi.org/10.1681/ASN. 2009070706

5. VCV000330316.2-ClinVar-NCBI. https://www.ncbi.nlm.nih. gov/clinvar/variation/330316/. Accessed 23 Feb 2021

6. Colten HR (1999) Complement and inflammation. In: Symposium in immunology VIII, Springer, Berlin, pp 3-13

7. Naughton MA, Botto M, Carter MJ, Alexander GJ, Goldman JM, Walport MJ (1996) Extrahepatic secreted complement C3 contributes to circulating C3 levels in humans. J Immunol (Baltimore, Md.: 1950) 156(8):3051-3056

8. Bruel A et al (2017) Hemolytic uremic syndrome in pregnancy and postpartum. Clin J Am SocNephrol 12(8):1237-1247. https:// doi.org/10.2215/CJN.00280117

9. Legendre CM et al (2013) Terminal complement inhibitor Eculizumab in atypical hemolytic-uremic syndrome. N Engl J Med 368(23):2169-2181. https://doi.org/10.1056/nejmoa1208981

Publisher's Note Springer Nature remains neutral with regard to jurisdictional claims in published maps and institutional affiliations. 